\title{
ESOS "MONSTRUOS DE CODICIA Y AUN DE LUJURIA": EL CURA Y EL ALCALDE, SEGUIMIENTO A UNA CRÍTICA DEL PODER EN LA LITERATURA LATINOAMERICANA EN AVES SIN NIDO Y HUASIPUNGO
}

Jorge Chen Sham

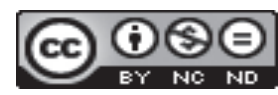

Esta obra está bajo una licencia Creative Commons 



\title{
ESOS "MONSTRUOS DE CODICIA Y AUN DE LUJURIA": EL CURA Y EL ALCALDE, SEGUIMIENTO A UNA CRÍTICA DEL PODER EN LA LITERATURA LATINOAMERICANA EN AVES SIN NIDO Y HUASIPUNGO
}

\author{
THOSE "MONSTERS OF GREED AND EVEN OF LUST": THE PRIEST \\ AND THE MAYOR, FOLLOW-UP TO A CRITICISM OF POWER IN LATIN \\ AMERICAN LITERATURE IN AVES SIN NIDO AND HUASIPUNGO
}

Jorge Chen Sham

\begin{abstract}
RESUMEN
En relación con el poder y la crítica de las autoridades que la ejerce, con Aves sin nido (1889), de Clorinda Matto de Turner, se perfilan dos figuras que la literatura latinoamericana catapulta, a la hora de desarrollar y atacar los desmanes del poder: se trata del alcalde (el gobernador en este caso concreto) y el cura, que Matto de Turner vilipendia y censura duramente desde el inicio de su novela, llamándolos "monstruos de codicia y aun de lujuria". Este artículo observa los alcances de lo monstruoso con figura humana y analiza la persistencia de la misma crítica en otra gran novela de la crítica social de la región andina, como lo es Huasipungo (1934), de Jorge Icaza, en donde ahora la censura del par cura/gobernador se dirige hacia el cura/latifundista. El punto de vista asumido en el análisis implica observarlos como tipos que ya la sátira clásica denuncia en relación con el poder y la prevaricación de sus cargos.

Palabras clave: Matto de Turner-Clorinda, Icaza-Jorge, Aves sin nido, Huasipungo, lo monstruoso humano.
\end{abstract}

\begin{abstract}
Regarding power and the critique of authorities who exercise it, in Aves sin nido, by Clorinda Matto de Turner, Latin American literature portrays two memorable characters who defy the excesses of power: the mayor (technically the governor in this case) and the priest whom the author vilifies and strongly censors from the start of the novel, calling them "monsters of greed and lust". This article traces the extent of the monstrous in humans and analyzes the persistence of such critique in another great novel from the Andean region, Huasipungo (1934), by Jorge Icaza, in which now the censorship of the pair priest/governor is directed at the priest/wealthy landowners. Here these characters will be analyzed as literary types denounced by classical satire for their abuses of power. Key words: Matto de Turner-Clorinda, Icaza-Jorge, Aves sin nido, Huasipungo, human monstrosity.
\end{abstract}

Dr. Jorge Chen Sham. Universidad de Costa Rica. Escuela de Filología y Lingüística. Costa Rica. Miembro correspondiente de la Academia Nicaragüense de la Lengua y la Academia Norteamericana de la Lengua Española. Correo electrónico: jorgechsh@yahoo.com

Recepción: 10- 02- 2015

Aceptación: 19- 06- 2015 
Las representaciones de lo monstruoso se dirigen, en primer lugar hacia esos seres fantásticos y sobrenaturales que el mito y las leyendas han construido; su consagración textual se produce en los bestiarios medievales y en los relatos de viajes de la Alta Edad Media. Más recientemente es la tradición genérica de lo gótico o el gusto romántico por la necrofilia y lo extraño lo que dará carta de naturalización de lo monstruoso en la literatura y el arte en general. Su génesis y la atracción fatal ejercida sobre los seres humanos partiría, como explica Rafael Ángel Herra, de esas oscuras tendencias atávicas, ya sea por contraponer el Bien y el Mal (1988, p. 21), ya sea por representar seres con un poder sobrenatural o sobrehumano que tienden a apabullar y a aniquilar.

Pero, ¿qué sucede cuando a los seres humanos se les califica de "monstruos"? Esta personificación de la desviación y de lo que está fuera de la norma no causa tanto miedo o terror, más bien le otorgamos un contenido psíquico y biológico a un ente ya no imaginario, que representa siempre lo abyecto, lo repulsivo. A este ser humano, calificado de monstruo, se le odia, se le denigra y se le rechaza, porque sus desviaciones y transgresiones nos parecen fuera de cualquier conducta aceptable o porque encarna aquello que la sociedad intenta reprimir y no desarrollar para la vida en sociedad. Así, en Aves sin nido, cuando Marcela en el inicio de la novela le pide a Lucía su socorro benefactor y le expone las exacciones y atropellos de las autoridades que representan el poder colonial, ella le increpa como reconociendo la situación:

\footnotetext{
- ¡Basta! no me cuentes más -interrumpió. Lucía, espantada por la gradación que iba tomando el relato de Marcela, cuyas últimas palabras alarmaron a la candorosa paloma, que en los seres civilizados no encontraba más que monstruos de codicia y aun de lujuria.

- Hoy mismo hablaré con el gobernador y con el cura, y tal vez mañana quedarás contenta - prometió la esposa de don Fernando, y agregó como despidiendo a Marcela: - Anda ahora a cuidar de tus hijas, y cuando vuelva Juan tranquilízalo, cuéntale que has hablado conmigo, y dile que venga a verme. (Matto de Turner, 1995, p. 28)
}

Observemos con atención que la calificación de "monstruos de codicia y aun de lujuria" no la hace Lucía sino la instancia narrativa. Como parte de esa sociedad patriarcal y, aun de resabios coloniales, Lucía tomará distancia frente a lo que ella denominará el proyecto civilizador de educar e insertar al indígena, tal y como la crítica ha destacado; eso es cierto dentro de esa actitud paternalista asumida aquí. Pero observemos que en la instancia narrativa asume el punto de vista de Lucía, para quien la "codicia" y la "lujuria" son pecados capitales desde la óptica de una moral cristiana que ella condena aquí. Esto es importante para comprender dos cosas: 1) La sanción moral que pesa ya sobre las figuras del poder, el "gobernador" y el "cura", con los cuales intentará mediar Lucía; y más significativo, aún, 2) La condena que ya expone el prólogo autorial de Clorinda Matto de Turner, cuando siguiendo el género de "novelas de costumbres" y la función didáctico-moral de la literatura en "reforma de algunos tipos [sociales]" (Matto de Turner, 1995, p. 21) declara en el "Proemio":

\footnotetext{
¿Quién sabe si después de doblar la última página de este libro se conocerá la importancia de observar atentamente el papel de las autoridades, así eclesiásticas como civiles, que vayan a regir los destinos de los que viven en las apartadas poblaciones del interior del Perú?

¿Quién sabe si se reconocerá la necesidad del matrimonio de los curas como una exigencia social?

Para manifestar esta esperanza me inspiro en la exactitud con que he tomado los cuadros del natural, presentando al lector la copia para que él juzgue y falle. (Matto de Turner, 1995, pp. 21-22)
}

En primer lugar, expone la escritora peruana, dentro de la función de que el escritor es testigo de primera mano de la realidad que acomete, el contrato de veracidad; este apunta hacia la conciencia y su compromiso reformador (Genette, 1987, p. 191). Eso sí, se trata de la 
responsabilidad que emprende el novelista en la óptica del proyecto liberal de la construcción de la nación "que debe destruir el viejo orden semifeudal, liberar la fuerza del trabajo indígena y propiciar un rápido proceso educativo que homologue a la población bajo el modelo de valores, intereses y hábitos de esa clase" (Cornejo-Polar, 1994, p. 19). Y en segundo lugar, en tanto es un caso tomado de la realidad verídica, la función del lector es aquí "juzgar" y "fallar" como si fuera un jurado; y el texto, la expresión en la tribuna del juzgado, porque se trata de convencer y persuadir, "qui en font un savoir agissant sur la motivation" (Gumbrecht, 1979, p. 364). ${ }^{1}$ El texto por venir, el que se abre al lector, se presenta como prueba de un caso en contra de lo que ella denomina como denuncia del "papel de las autoridades, así eclesiásticas como civiles", lo cual subraya la coherencia ideológica que Alberto Tauro ve en la novela.2 Esto también explicaría la polémica que desata la novela y sus rumores de que el arzobispo de Lima había excomulgado a la escritora por sus ataques en contra del estamento eclesiástico (Peluffo, 2005, p. 38).

Con ello, en una perspectiva paratextual, el prólogo proporciona unas claves interpretativas en tanto indicaciones contextuales que apuntan directamente al papel del lector y, por lo tanto, se arriesga una "declaración de intenciones". Promulga, en efecto, un control sobre el sentido verdadero y correcto de la novela (Genette, 1987, p. 205) y, en tanto reformadora de las costumbres morales, hace que su denuncia recaiga sobre las figuras del poder, lo que habla de por sí de esa capacidad de la sátira en contra de la autoridad de reactualizarse históricamente (Chen-Sham, 2002, p. 232) y de las polémicas de una recepción que nace bajo el riesgo interpretativo en cuanto a las posibilidades de que los lectores tomen partido frente a lo que se critica/denuncia en la obra por un lado, y por otro, que el escritor que asume estos rasgos, eminentemente de la sátira, es más o menos consciente de lo que puede acarrear su libro (Chen-Sham, 1999, p. 66).

Recordemos que la actitud satírica-reformadora siempre ha apuntado contra el poder y las instituciones que lo detentan. Uno de los temas predilectos de la sátira medieval fue el ataque de los hombres de Iglesia, representantes del poder más denostado y baluartes en los muros de sus conventos, del saber y de la salvación de los seres humanos (Hodgart, 1969, pp. 39-46). Una de las manifestaciones más acusadas de la sátira medieval es la poesía anticlerical, cuyos retratos de monjes licenciosos y golosos, o de obispos concupiscentes son harto conocidos. ${ }^{3}$ También se encuentran las famosas danzas de las muertes medievales, en donde la Muerte, con su guadaña, viene a juzgar a todos los estados-oficios. De ella nadie se salva porque desde el papa y el monarca hasta las distintas corporaciones, nadie se librará de su juicio moral. En cuanto, a las dignidades eclesiásticas, dos interesan porque en ellas están resumidas las críticas estereotipadas propias del retrato del cura; por ejemplo, en el abad se censura su gula: ${ }^{4}$

\footnotetext{
Don abad bendito, folgado, vicioso, que poco curaste de vestir cilicio; abrazadme agora, seredes mi esposo pues que deseaste placeres e vicio : Ca yo só bien presta a vuestro servicio, habedme por vuestra, quitad de vos saña, Que mucho me place con vuestra compaña. (La danza de la muerte, 1968, pp. 111-112)
}

Observemos cómo la Muerte sin reparos reprehende al abad por afanarse con los "placeres" de la carne, esto queda sobreentendido en el contexto medieval en el que la castidad y la pobreza se destacan sobre el voto de la obediencia y, en ese sentido, falta el monje a sus 
votos. Por otra parte, en el retrato del arcediano de La danza de la Muerte, se encuentra la crítica a las dignidades eclesiásticas a causa de su poco celo profesional y lo desenmascara quitándole el signo propio de su estado, el bonete, porque se ha entregado a la concuspicencia y a la lascivia:

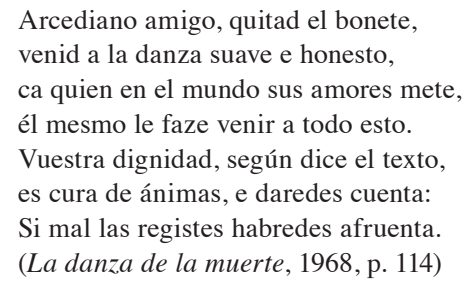

En cuanto a la autoridad "civil" (y lo ponemos entrecomillas para destacar que esta no existe en el contexto medieval de una mentalidad estamental y regida por los fueros de la nobleza), corresponde al oficio de abogado, cuyo rasgo más conspicuo es la prevaricación; la Muerte le espeta al "letrado" lo siguiente:

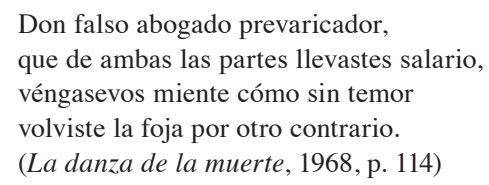

Recordemos que la prevaricación se relaciona con la utilización del cargo para su propio provecho personal y, desde la Edad Media, la denuncia de lo que hoy entendemos por el enriquecimiento ilícito y el interés propio del funcionario "público" se condensa en la figura del abogado, al servicio de la administración de la monarquía. Volviendo a "La danza de la Muerte" medieval, se le acusa al abogado de servir a las dos partes y a falsificar sus escritos en procura de su propia codicia. Su representación a la altura del Siglo de Oro español ha cambiado, pues se concreta en la figura del letrado, abogado y funcionario al servicio de la administración y justicia (Márquez-Villanueva, 1985, p. 203). En este sentido, nos interesa la segunda acepción que recensa Sebastián de Covarrubias en su Tesoro de la Lengua Castellana o Española, porque no solo explica el sentido restringido de "letrado" en el Siglo de Oro, sino también porque su explicación está motivada por este enjuiciamiento de suplantación: "el que professa letras, y hanse alçado con este nombre los juristas abogados" (Covarrubias, 1979, p. 763). En este contexto áureo, no es gratuito que sea la sátira, sobre todo la de Francisco de Quevedo, la que nos ofrece un retrato de letrado, acusado de prevaricar el lenguaje y engañar para su provecho personal; sus rasgos más conspicuos serían su afán de lucro (enriquecimiento) y su saber superfluo que esconde su mediocridad (falsas apariencias). Lía Schwartz-Lerner resume así el estereotipo del letrado según la codifica las sátiras quevedianas:

\footnotetext{
Todos ellos engañan con una apariencia exterior de idoneidad y competencia que oculta sus malévolas intenciones. Para ser letrado, en consecuencia, basta asumir una máscara de hombre sabio, tener una imponente biblioteca y citar autoridades jurídicas que correspondan a la vestimenta jurídica de la profesión. (Schwartz-Lerner, 1986, p. 40)
}

En este retrato dominan los rasgos que evocan la corrupción y las apariencias de letrado. La máscara aquí contribuye al dolo y al prevaricato, ya que el letrado oculta sus verdaderas intenciones y piensa en primer lugar en su bienestar personal, faltando a las obligaciones propias de su estado y oficio, por lo cual la denuncia que hace Quevedo en sus 
sátiras se dirige hacia el egoísmo y hacia la avidez de lucro del letrado con el fin de subrayar "la corrupción de los hombres en casi todos los estados y profesiones" (Schwartz-Lerner, 1986, p. 32), insistiendo en los tipos del "juez prevaricador" y del "abogado corrupto".

Así, la autoridad que ejerce el poder se cubre de unos rasgos que Matto de Turner retoma de una tradición satírica, eso es cierto, pero cuyo contexto socio-histórico moldea y, al mismo tiempo, trasvasa y condensa en otras figuras para el caso latinoamericano, en el gobernador del pueblo (llámese el alcalde) y en el cura. Ahora bien, ¿por qué les endilga (perdóneseme el término) y les atribuye los pecados capitales de la codicia y de la lujuria? La avaricia es "el ansia por adquirir y guardar dinero, tesoros u otra cosa de valor" (CallesVales, 2000, p. 147) y entra en equivalencia con la "codicia", la cual se define como "[a] mbición desordenada de riquezas” (García-Pelayo y Gross, 1976, p. 241). Mientras tanto, la lujuria se le denomina "también lascivia, concupiscencia, sensualidad o salacidad. Se aplica, como defecto, a las personas inmoderadas en sus deseos sexuales" (Calles-Vales, 2000, p. 179). En los dos casos anteriores, se trata de un vicio, de un exceso y de una capacidad para no moderar (controlar) su afán no solo de riqueza sino también sus deseos sexuales. Por ello, las personas con estos defectos o vicios serían reprehensibles o censurables, en la medida en que su inmoderación en controlar sus impulsos son asimilados al monstruo; podría justificarse por eso en esa dicotomía fundante sobre la cual se sostiene toda nuestra metafísica occidental, basada en esa oposición entre el Bien y el Mal. En tanto que "el hombre necesita del mal para afirmarse como bueno" (Herra, 1988, p. 25), nace el monstruo en esa pugna o dilema que lo conceptualiza como contrapunto a la bondad y, por lo tanto, encarnación de la maldad destructiva en la que podemos exorcizar nuestros fantasmas y miedos más profundos; dice al respecto Herra: "Gracias al monstruo, a su principio ético, los hombres se sienten a salvo del mal: la destrucción corre por cuenta de las bestias, y el monstruo aparece entonces engañosamente, en vez del hombre, como inventor del mal con sus actos" (1988, p. 26).

De esta manera, a partir de esta asociación con la maldad, el monstruo entra en una sistemática en la que sus vicios reprehensibles, a causa del exceso o del descontrol de lo que el ser humano virtuoso regula, se traducen en su retrato físico y moral. Esto es lo ocurre en Clorinda Matto de Turner cuando ya la descripción del cura don Pascual, bajo de estatura y rechoncho, delata su poco aseo personal, mientras que su vestimenta es un primer síntoma de su impostura: "vestido con una imitación de sotana de tela negra, lustrosa, mal tallada, y peor atendida en el aseo" (Matto de Turner, 1995, p. 33). Se refuerza luego cuando la instancia narrativa cuestiona su poca preparación y la poca confianza que despertaba su nivel de estudios: "inspiraba desde el primer momento serias dudas de que, en el Seminario, hubiese cursado y aprendido Teología ni Latín" (Matto de Turner, 1995, p. 33). Toda la tradición de la sátira de los falsos y pedantes subraya la poca preparación y la falta de celo de quien tiene un barniz de estudios y es un ignorante pretencioso (Chen-Sham, 1999, pp. 166-167), porque, detrás de su máscara, finge; su finalidad es lucrar de su profesión.

Pero en el caso del cura, el temor de las indígenas como Marcela de "entrar al servicio de la casa parroquial" (Matto de Turner, 1995, p. 33), se explica a continuación cuando, en forma contundente, la instancia narrativa observa como si estuviera haciendo un estudio médico-moral para detectar en su físico sus taras morales: "Para un observador fisiológico el conjunto del cura Pascual podía definirse por un nido de sierpes lujuriosas, prontas a despertar al menor ruido causado por la voz de una mujer" (Matto de Turner, 1995, p. 33). La imagen de su cuerpo convertido en un "un nido de sierpes lujuriosas" despierta toda nuestra atención, toda 
vez que se relaciona con el simbolismo maléfico de la serpiente; ${ }^{6}$ su lujuria y la voluptuosidad, que se asocian en la literatura finisecular decadente a la femme fatale, se ponen al servicio de un código negativo que señala una evaluación de rechazo y de censura (Praz, 1977, p. 212). Del monje glotón y lascivo de la literatura medieval, pasamos al cura lujurioso que Clorinda Matto de Turner vilipendia, porque prevarica y delinque en su afán perverso de lujuria.

No se escapa tampoco de esta sanción moral el gobernador del pueblo, don Sebastián Pancorbo, a quien la instancia narrativa nombra con el irónico tratamiento de "su señoría [...], de cruz alta, capa nueva, salero de plata" (Matto de Turner, 1995, p. 34); el arreglo del vestido delata su compostura y su boato de apariencia, pues señala luego su incipientes estudios de primaria. Además, gracias a un matrimonio de conveniencia, ha llegado al "puesto más encumbrado que se conoce y a que se aspira en un pueblo" (Matto de Turner, 1995, p. 35), de manera que se condena su arribismo y su falta de preparación para servir al pueblo. En cuanto a su retrato físico, la instancia narrativa sanciona sus inclinaciones viciosas en las que lo fisiológico se muestra como signo de sus tendencias hacia el dinero y las mujeres: "sus ojos negros, vivos y codiciosos, denuncian en mirada inclinada a la visual izquierda que no es indiferente al sonido metálico, ni al metal de una voz femenina” (Matto de Turner, 1995, p. 35). Ingeniosa es la equivalencia entre el "sonido metálico" de las monedas y el timbre metálico, agudo, de una voz que suena femenina; su comparación se establece a partir del elemento in absentia que permite la comparación: las monedas de plata y el timbre argentado.

Por lo anterior, esos ojos "codiciosos" por el sonido de las monedas también se mueven al sonido de las voces femeninas que tanto lo atraen hasta que se inclinen hacia la izquierda, señal de una tendencia "siniestra". La instancia narrativa anota un defecto físico que él intenta ocultar: "El dedo meñique de la mano derecha se le torció siendo mozo, [...] y desde entonces usa un medio guante de vicuña, aunque maneja con gracia peculiar aquella mano" (Matto de Turner, 1995, p. 34). Esconde su deformidad (Guyard, 2009, p. 485) con un recurso que le sirve para enmascarar y disfrazar su físico. ${ }^{7}$ Es decir, se crea una atmósfera de desconfianza y de suspicacia ante estos dos personajes, de los que no se puede esperar nada bueno como sucede a continuación, cuando Lucía les plantea su caso en relación con la india Marcela. Tiene razón Marta A. Umanzor en observar ese papel protagónico de Lucía, de la mujer “[...] que ocupa el centro del espacio y la hegemonía del discurso de denuncia” (1999, p. 68) y, sin preámbulos, increpa a las autoridades que acaban de entrar a su casa. Dirigiéndose en primer lugar al cura le suplica recordándole los valores de la caridad y del amor al prójimo:

\footnotetext{
-En nombre de la religión cristiana, que es puro amor, ternura y esperanza; en nombre de vuestro Maestro, que nos mandó dar todo a los pobres, os pido, señor cura, que deis por terminada esa deuda que pesa sobre la familia de Juan Yupanqui. ¡Ah![,] tendréis en cambio doblados tesoros en el cielo... (Matto de Turner, 1995, p. 35)
}

En la contigüidad de la novela, en primer lugar, Lucía utiliza la misma argumentación pecuniaria que tanto pondera el señor cura. Apela a la recompensa de la vida ultraterrena, cuando los "doblados tesoros en el cielo" serán la gratificación a sus acciones en favor del bien del prójimo. En segundo, el pecado escandaloso de la codicia ahora se explicita en una situación concreta, su relación con la "deuda" a la que alude Lucía se contextualiza en la petición planteada por Marcela en el Segundo Capítulo de la Primera Parte. La "visita del reparto" (Matto de Turner, 1995, p. 26) es inminente con el ulterior apremio y multa si no se paga la cuota impuesta por el terrateniente y que forma parte del sistema colonial. La instancia narrativa luego se da a la tarea de explicar al lector este régimen cuasi feudal de explotación agraria, el cual consiste en 
adelantar dinero a los indios que trabajan la lana de alpaca, el cual cobran en un "rendimiento de quinientos por ciento; usura que, agregada a las extorsiones de que va acompañada, casi da la necesidad de la existencia de un infierno para esos bárbaros" (Matto de Turner, 1995, p. 29). Es decir, la codicia está asociada en Aves sin nido a la usura, reprochable ya desde las condenas bíblicas y, al sistema de sanciones en las que se institucionaliza las figuras tanto del cobrador y del cacique como la del cura. Tienen su asidero en una práctica que condena, indica Matto de Turner a "un mundo de pobreza y dolor infamante" (1995, p. 31). La respuesta del cura Pascual no se hace esperar; sus palabras justifican la tradición y el statu quo sobre la que se basan sus prerrogativas y poder consuetudinario, que vienen del sistema colonial:

\footnotetext{
- Señorita mía - repuso el cura Pascual arrellanándose en el asiento, y apoyando ambas manos en los brazos del sillón - todas esas son tonterías bonitas, pero, en el hecho, ¡válgame Dios! [,] ¿quién vive sin rentas? Hoy, con el aumento de las contribuciones eclesiásticas y la civilización decantada que vendrá con los ferrocarriles, terminarán los emolumentos: y... y... de una vez doña Lucía, fuera curas; ¡nos moriremos de hambre...

- ¿A eso había venido el indio Yupanqui? - agregó el gobernador, en apoyo del cura, y con tono de triunfo terminó recalcando la frase para Lucía - francamente, sepa usted, señorita, que la costumbre es ley, y que nadie nos sacará de nuestras costumbres, ¿qué?... (Matto de Turner, 1995, pp. 35-36)
}

Si al señor cura le preocupan las "rentas" que se originarían en tasas e imposiciones calificadas de injustas y exorbitantes en relación con el uso de la tierra, para el gobernador lo que debe imperar es la "costumbre" haciendo que las leyes sean de naturaleza natural y, en este caso, divinas, a causa de las cuales el mundo así ordenado y jerarquizado encuentra su derecho en ellas. Cuestionarlas sería traerse abajo los fundamentos de la sociedad, frente a la posición que sostiene Lucía, portavoz como lo ve el cura, del discurso de la modernidad civilizatoria en la imagen de los ferrocarriles. ${ }^{8}$ La instancia narrativa termina advirtiendo la misma sintonía en la que están tanto el cura y el gobernador, de la siguiente manera en un juego de miradas complacientes: "Las cortas frases cambiadas habían puesto en transparencia el fondo moral de aquellos hombres, de quienes nada debían esperar, y sí temerlo todo" (Matto de Turner, 1995, p. 36). Es decir, de manera implícita, alude la escritora peruana a conspiración de las autoridades en defensa de sus intereses; su toma de posición significa que ellos se juntan para tramar algo. Recordemos que "conspirar" viene en latín de la raíz spirare, "soplar, respirar"; etimológicamente conspirare significa "respirar juntos" y de ahí su significado figurada de "estar de acuerdo" (Corominas y Pascual, 1992, p. 748). El verbo conspirar denota la oposición y el enfrentamiento de quien se alía a otro, ${ }^{9}$ confabulándose en contra de las ideas de Lucía ubicadas en la defensa de los indígenas.

La misma crítica se repite en Huasipungo (1934), en donde, don Alfonso Pereira, quien representa ahora el potentado del latifundio aliado al poder extranjero para traer la carretera a la región andina de Cuchitambo, pretende explotar la madera de sus tierras y poder pagar así sus deudas. Desde el principio de la novela, se marca el desdeño y la actitud de superioridad con los que los blancos tratan y miran a los indígenas y, en relación con la "lujuria" la instancia narrativa de Huasipungo abiertamente marca esas relaciones de poder entre amo/siervos dentro de un conflicto entre explotador/explotados, terrateniente versus huasipungueros; se trata de un sistema feudal que empieza a transformarse (solamente en superficie) con la venida del ferrocarril (Cueva, 1988, p. 639). Desde este pensamiento cuasi-feudal, la dominación de las indias no solo se plantea como una conquista legítima, sino también como una posesión dentro de esa mentalidad de derecho de pernada medieval, que el conquistador español y después el terrateniente reproduce en materia de procrear/acostarse con las indias. ${ }^{10}$ Observemos lo que sucede cuando don Alfonso pregunta por una de sus criadas: 
- ¿Y qué es de la Juana, que no la veo?

-En la cocina, pes. ¡Juanaaa! ¡Aquí está el señor de Cuchitambo!

-Ya voooy.

Casi siempre la mujer - apetitosa humildad en los ojos, morena de bronce en la piel, amplias caderas, cabellos negros en dos trenzas anudadas con pabilos, brazos bien torneados y desnudos hasta más arriba de los codos - aparecía por una puerta lagañosa de hollín [...]. A la vista del omnipotente caballero la chola enrojecía, se pasaba las palmas de las manos por las caderas y murmuraba:

- ¿Cómo está, pes, la niña grande? (Icaza, 2003, pp. 84-85)

La calificación de "apetitosa" no es inocente toda vez que la focalización interna descansa sobre don Alfonso, pues la mirada del cuerpo de la mujer en los ojos del terrateniente, de arriba hacia abajo, se fija en aquellas partes que más llaman la atención del latifundista; reclama con sus ojos la posesión, mientras que la sumisión/aceptación se manifiesta en la connivencia posible en el verbo sonrojar y en la praxémica que desarrolla a continuación el amo, quien con sus manos en las caderas, en posición de "gallo", hace una pregunta que no es anodina en este contexto, pues interroga por otra "gallina" de su corral. Tal correlación con las aves del corral no es antojadiza, una página y media antes de esta escena, cuando Andrés Chiliquinga regresa a su choza y no encuentra a su Cunshi (su esposa); ella estaba recogiendo leña en la sierra. Enfurecido y molesto, salta sobre ella para pegarle; observemos lo que indica la instancia narrativa:

De un salto felino él se apoderó de la longa por los cabellos. Ella soltó la leña que había recogido y se acurrucó bajos unos cabuyos como gallina que espera el gallo. Si alguien hubiera pretendido defenderla, ella se encararía de inmediato al defensor para advertirle, furiosa: «Entrometidu. Deja que peguee, que mate, que haga pedazus; para esu es maridu, para esu es cari propiu...» (Icaza, 2003, p. 82)

Las simbologías del gallo (que le salta encima en posición de dominación sexual) y de la gallina están aquí para describir unas relaciones basadas en la hegemonía del macho y su poder sobre la hembra. Es su pertenencia, eso es cierto, y en ese sentido delata toda ese sistema de relaciones que el saber paremiológico enquista bajo el refrán, “¡Cuánto más te quiero, más te aporreo!", mientras la mujer asienta y acepta esta condición de amo/esclavo. No nos extrañe, entonces, la contigüidad de las dos escenas, cuya justificación se halla en el sistema feudal; pero en el caso de Andrés Chilinquinga, está permitido, como indica la propia "Cunshi”, porque se trata su "cari propiu", mientras que en otro caso, estamos en el derecho de "pernada". Los ojos de don Alfonso y la descripción de la escena que hace la instancia narrativa tienen como presupuesto la "lujuria" de los ojos lujuriosos dentro de un sistema de dominación patriarcal.

En cuanto a la figura denostada del cura, una vez instalado en la hacienda, don Alfonso visita regularmente el pueblo como quien explora sus dominios territoriales; aquí entra en juego la figura del cura y la instancia narrativa habla abiertamente de una "alianza" de sus intereses:

\footnotetext{
Los paseos del dueño de Cuchitambo terminaban generalmente en el curato. Largas, sustanciosas y a veces entretenidas conversaciones sostenían terrateniente y cura. Que la patria, que el progreso, que la democracia, que la moral, que la política. Don Alfonso, en uso y abuso de su tolerancia liberal, brindó al sotanudo una amistad y una confianza sin límites. El párroco a su vez — gratitud y entendimiento cristianos - se alió al amo del valle y la montaña con todos sus poderes materiales y espirituales.

- $\mathrm{Si}$ así fueran todos los sacerdotes el mundo sería un paraíso - afirmaba el uno.

- Su generosidad y su energía hacen de él un hombre bueno. Dios ha tocado en secreto su corazón pregonaba el otro. (Icaza, 2003, p. 86)
}

Otra vez más, se insiste en este contexto de prevaricación y de corrupción por parte de autoridades civiles y religiosas, de intereses en común entre el cura y el terrateniente. Como en Aves sin nido, el poder civil y religioso están indisolublemente ligados para que los desmanes 
y sus exacciones se trasladen hacia el pueblo que está bajo su jurisdicción. El cura entra con todo el beneplácito en el plan de don Alfonso, interviene no solo como su aliado en procura de comprar las tierras del Valle al mejor precio, sino cuando catequiza y trae a las almas al camino cristiano piensa en adscribirlos a la jurisdicción de la Iglesia para cobrar su parte que le corresponde de lo que deben los indios dar en forma de diezmo. La forma despectiva de su trato para con los huasipungueros no sorprendería a don Alfonso, venido de la ciudad y perteneciente a una familia patricia; pero analicemos el siguiente diálogo en donde las palabras del cura delatan su menosprecio y el poco celo pastoral que conllevan cuando se les explota en función de la mano de obra posible:

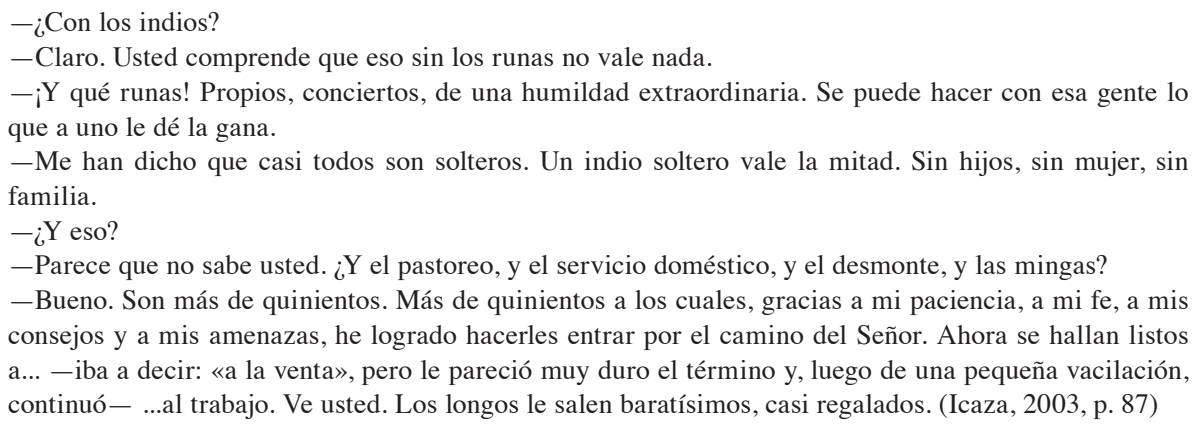

Frente al latifundista codicioso y lujurioso, el cura también habla de los seres humanos como si fueran animales de carga y esclavos que solamente apuntan al enriquecimiento del sistema feudal y, encima de eso, faltando a su obligación de pastor de almas, al servicio de los "hijos de Dios" se actualizaría la famosa Controversia de Valladolid en la que fray Bartolomé de Las Casas defendía a los indígenas en contra de Ginés de Sepúlveda sobre la guerra justa y las exacciones en contra de ellos. ${ }^{11}$ En su Tratado de 1552, "sobre la materia de los indios que se han hecho en ellas esclavos", Las Casas describe las formas de encomienda y repartimiento de los indios, en donde las triquiñuelas y mentiras están a la orden del día. Desde la Conquista y Colonia, los indios fueron considerados la mano de obra que buscaban los españoles para enriquecerse y lucrar:

\footnotetext{
Ido allá, hallábalos [se refiere a los indios] en sus casas o en sus labranzas trabajando, y mataba los que quería, y los demás atábalos, trayéndolos como habidos de buena guerra y luego se los herraban por esclavos. Otro enviaban a decir a los caciques que luego viniesen cincuenta indios para trabajar en tal labranza, o que les trajesen tantas cargas de maíz, o de madera o [sic] otras cosas, y al tiempo que los querían despedir decíanles que se quedasen dellos diez o quince hombres para traer hierba a los caballos aquel día o dos; e idos los otros, los entregaban a quien ya los tenían vendidos por esclavos, y los metían en el barco o navío y así los llevaban. Otros decían que no os los vendían por esclavos, sino por naborías. Naboría quiere decir que le sirve continuamente en casa, de la misma manera que esclavo, sino que pública ni secretamente los pueden vender sin pena. (Las Casas, 1997, p. 517)
}

La mentira, la manipulación y el desprecio censura Las Casas para que surja en su relato la crítica sobre todo, de la codicia del conquistador español. Este breve excurso por Las Casas permite comprender cómo está anquilosado en esta mentalidad colonial el menosprecio y la desvalorización del indio, que las críticas de Clorinda Matto de Turner y Jorge Icaza llevan a las etopeyas, al retrato moral y a las conductas de figuras que representan la autoridad. En el caso de Aves sin nido y de Huasipungo, el sistema esclavista sigue perpetuándose a través de la representación de estas dos figuras execrables y "monstruosas", las cuales se deforman en el vicio de uno de esos pecados capitales desde 
el punto de vista del catolicismo como es la lujuria; el abuso de seres humanos en aras del lucro y de la codicia, así como la prevaricación de la autoridad.

En la configuración estética de lo monstruoso, tal y como vimos en Clorinda Matto de Turner, el desagrado o la repugnancia que le provoca a la instancia narrativa tanto el cura como el gobernador, configuran una crítica al poder que, en Aves sin nido, está en relación con el efecto de lo monstruoso sobre el espectador/lector. El monstruo se presenta y es visto como alguien distinto y diferente; de ahí su anormalidad, su excepcionalidad, de una identidad captada como singularidad (Herra, 1988, p. 24) en las que "las añazas del cura y los abusos del gamonal" (Fernández, 2003, p. 44) en Icaza, son solamente una transformación histórica a los modelos satíricos tradicionales, del abad/canónigo y del abogado/letrado, glotones, corruptos, prevaricadores. En esta actualización socio-histórica la configuración estética de la sátira posee toda su fuerza pragmática, cuando su interés primordial es denunciar y juzgar lo que a los ojos de la instancia narrativa es intolerable y abominable en la situación presente del texto literario.

\section{Notas}

1. Se refiere, por lo tanto, al género deliberativo-judicial, cuya función es la de juzgar con arreglo a categorías como culpable/ inocente o factible/ no factible (Gumbrecht, 1979, p. 364).

2. Se trata de "reconocer la mayor significación de Aves sin nido, por la novedad del tema, la configuración de los personajes y la fuerte denuncia que se negó ignorar" (1976, p. 32).

3. Se trata de los poemas de los goliardos estudiantes vagabundos que recorrían la Europa de las universidades y estaban muchas veces al servicio de la propia Iglesia. La colección más famosa son los Carmina Burana, descubiertos en el monasterio de Beneditbeuern, en los que hay muchos poemas satíricos cuyos "temas de queja son la curia papal, los obispos y los monjes, que son acusados de simonía o comercio con los puestos eclesiásticos, de avaricia, de glotonería y de la mayor parte de los pecados capitales" (Hodgart, 1969, p. 44).

4. Es una de las tantas dignidades eclesiásticas que juzga la Muerte, porque lo hace también con el obispo, y el canónigo, etc. En el caso del abad y en el siguiente, el arcediano, sus críticas son las que más se ajustan a las conductas reprochables por Matto de Turner.

5. Respeto la ortografía del original en esta y las otras citas.

6. También con la cabeza de la Gorgona-Medusa, de cuya cabeza sangrante surgen serpientes.

7. En relación con el retrato físico de quienes son codiciosos, "[s]e representa habitualmente como un individuo encorvado y huraño, el cual se frota las manos como si esperase acaparar los bienes ajenos. Este individuo se presenta enjuto y comido de carnes, porque, en virtud de su codicia, teme gastar incluso lo necesario" (Calles-Vales, 2000, p. 147).

8. Se trata de un lugar ya de la crítica sobre esta novela. No quiere volver sobre esto.

9. Aunque su sentido remite primeramente a sublevarse y amotinarse contra el superior o soberano.

10. Es el mismo esquema que las telenovelas reproducirán en el derecho de los señores/señoritos de casa de violar/seducir a las criadas, indígenas primero, y luego pobres.

11. El desarrollo de la Controversia rebasa este artículo.

\section{Bibliografía}

Calles-Vales, J. (2000). Refranes, proverbios y sentencias. Alcobendas: Editorial Libsa.

Chen-Sham, J. (1999). “Fray Gerundio de Campazas” o la corrupción del lenguaje: Sátira y escamoteo autorial. San José: Editorial de la Universidad de Costa Rica.

Chen-Sham, J. (2002). La sátira del letrado en el siglo XVIII español: ¿cliché o sociotipo? Dieciocho. 25 (2), 229-242. 
Corominas, J. y Pascual, J. A. (1992). Diccionario crítico-etimológico castellano e hispánico. (Vol. 2). Madrid: Editorial Gredos.

Covarrubias, S. de. (1979). Tesoro de la Lengua Castellana o Española. Madrid: Ediciones Turner.

Cornejo-Polar, A. (1994). La literatura hispanoamericana del siglo XIX: Continuidad y ruptura (Hipótesis a partir del caso andino). Por B. González-Stephan et ál. (Eds.). Esplendores y miserias del siglo XIX. Cultura y sociedad en América Latina. (11-23). Caracas: Monte Ávila Editores/ Equinoccio/ Ediciones de la Universidad Simón Bolívar.

Cueva, A. (1988). Literatura y sociedad en el Ecuador: 1920-1960. Revista Iberoamericana. 54 (144-145), 629-647.

Fernández, T. (2003). Introducción. Por J. Icaza. Huasipungo. (5 ed.). (9-57). Madrid: Ediciones Cátedra.

García-Pelayo y Gross, R. (1976). Pequeño Larousse ilustrado. París: Ediciones Larousse.

Genette, G. (1987). Seuils. París: Éditions du Seuil.

Gumbrecht, H. U. (1979). Persuader ceux qui pensent comme vous: Les fonctions du discours épidictique sur la mort de Marat. Poétique. 39, 363-384.

Guyard, É. (2009). La re-motivation du monstre dans le récit fantastique contemporain: La rosa de los vientos de Gonzalo Torrente Ballester (1985). Por F. Desvois (Ed.) Le monstre: Espagne \& Amérique Latine. (485-500). París: L'Harmattan.

Herra, R. Á. (1988). Lo monstruoso y lo bello. San José: Editorial de la Universidad de Costa Rica. Hodgart, M. (1969). La sátira. Madrid: Ediciones Guadamarra.

Las Casas, B. (1997). Tratados. México, D. F.: Fondo de Cultura Económica.

Matto de Turner, C. (1995). Aves sin nido. Lima: Editorial Mantaro.

Márquez-Villanueva, F. (1985). Letrados, consejeros y justicia (artículo-reseña). Hispanic Review. 53 (2), 201-27.

Peluffo, A. (2005). Lágrimas andinas: Sentimentalismo, género y virtud republicana en Clorinda Matto de Turner. Pittsburgh: Instituto Internacional de Literatura Iberoamericana.

Praz, M. (1977). La chair, la mort et le diable dans la littérature du XIXè siècle: Le romantisme noir. París: Éditions Denoël.

Rodríguez-Puértolas, J. (Ed.). (1968). La Danza de la Muerte. Poesía de protesta en la Edad Media castellana. (102-125). Madrid: Editorial Gredos.

Schwartz-Lerner, L. (1986). El letrado en la sátira de Quevedo. Hispanic Review. 54 (1), 27-46.

Tauro, A. (1976). Clorinda Matto de Turner y la novela indigenista. Lima: Dirección Universitaria de Biblioteca y Publicaciones.

Umanzor, M. A. (1999). El discurso de la mujer en el mundo artístico de Clorinda Matto de Turner. Por L. A Jiménez (Ed.) La voz de la mujer en la literatura hispanoamericana fin-de-siglo. (61-77). San José: Editorial de la Universidad de Costa Rica. 
